\title{
Authenticity of Discourse Signaling Cues in Second Language Lecture Comprehension Tasks
}

\author{
Wang Haiping \\ School of Foreign Studies \\ East China University of Political Science and Law \\ Shanghai, China \\ cathy_pingen@163.com
}

\begin{abstract}
The paper aims to explore authenticity of discourse signaling cues in L2 lecture comprehension tasks by contrasting the quantity of discourse signaling cues in the script of an authentic lecture taken from Michigan's Academic Spoken Corpus and that of a mini-lecture taken from a TEM 8 listening comprehension subtest. The findings have shown that there is a higher frequency of macromarkers and a lower frequency of micromarkers in the TEM 8 script. In order to improve authenticity of academic listening tests, it is important to add authentic discourse signaling cues to the script or the test-takers' academic listening competence might not be tested as expected.
\end{abstract}

Keywords-authenticity; discourse signaling cues; second language; lecture comprehension tasks

\section{INTRODUCTION}

Lecture comprehension depends less on comprehension of individual sentences, and more on interrelation of them and the macro-text structure. Logical relation of sentences and the macro as well as micro structure of an academic lecture are indicated by cues. That is to say, if learners fail to recognize the cues that signal sequence of thoughts in the lecture and the organization of it, most probably, he or she will meet difficulties in grasping the main points of the lecture. Those cues are actually metalinguistic devices that function as directional guides to remind listeners of the incoming information [1].

\section{Discourse Signaling Cues In TeXt Processing RESEARCH}

There are plenty of researches probing into the function of discourse signaling cues in L1 and L2 reading comprehension while little attention has been paid to the role of cues in listening comprehension. In order to make clear of discourse signaling cues and scientifically categorize them, it is important to analyze the macrostructure as well as the microstructure of academic lectures first. The notion Macrostructure was actually initiated by a German linguist Bierwisch in the year of 1965. In 1980, van Dijk published his book Macrostructures: An Interdisciplinary Study of Global Structures in Discourse, Interaction, and Cognition, a cornerstone of research on macrostructure of discourses. Thereafter, he presented his important theory of multi-layer analysis of discourse as follows:

a. microstructure $\rightarrow$ sentences, phrases, words

\author{
b. macrostructure $\rightarrow$ semantic content \\ c. superstructure $\rightarrow$ conventional form of discourse [2]
}

According to van Dijk, macrostructures are the semantic content for the terminal categories of superstructural schemata. Though cognitive comprehension of macrostructures and superstructures is an integrated process, macrostructures are defined by so called "macrorules" [2] based on the meanings of the sentences of a discourse. Macrorules are employed to process those propositions expressed by sentences in a way of deletion, generalization and construction:

1. DELETION: Given a sequence of propositions, delete each proposition that is not an interpretation condition (e.g., a presupposition) for another proposition in the sequence.

2. GENERALIZATION: Given a sequence of propositions, substitute the sequence by a proposition that is entailed by each of the propositions of the sequence.

3. CONSTRUCTION: Given a sequence of propositions, replace it by a proposition that is entailed by the joint set of propositions of the sequence. [2]

In one word, macrorules help generate the global meaning of a discourse from local sentential meanings and macrostructures of discourses are composed of semantic units that cover a sequence of propositions. So, when we come to the research question on how to categorize discourse signaling cues, van Dijk's macrostructure theory is helpful. We might attempt to define macro discourse signaling cues as those indicating the gist or general ideas of a discourse or essential semantic components of a discourse while micro discourse signaling cues as those indicating sentential or phrasal relations.

The afore-mentioned assumption contains some validity according to the research conducted by Chaudron and Richards [3]. They categorized discourse signaling cues into macro- and micromarkers. That is to say, macromarkers refer to the cues that function at the macro discourse level to indicate the relationship between main parts or transitions of the discourse. For example, sentences like "Today, I am going to talk about writing." can be viewed as macromarkers. On the other hand, micromarkers refer to cues that function at the micro discourse level to mark relationship between sentences or as pause fillers. And, so, well, um, etc. can all be called micromarkers. Chaudron and Richards' classification of discourse signaling cues pertains to van Dijk's paradigm of discourse structures. 
Researchers also name those macromarkers as metapragmatic signals which facilitate comprehension and function as "macroorganizers" as they signal what is coming up in the lecture, e.g. "Let me start with.... (topic marker); So let me shift to... (topic shifter); To sum up... (summarizer), etc." Academic lectures of a written style are often hard to follow because they lack such signaling cues.

Though literature concerning the role of discourse cues in listening comprehension has been rare, there are still a number of empirical researches which have addressed the issue thoroughly. For example, Tompson [4] compared metadiscourse and intonational signaling cues in undergraduate lectures with recordings of commercial EAP listening materials. Pickering [5] compared native-speaker and international teaching assistant's use of pitch and pause cues to create 'intonational paragraphs' in their classes. Rickards, et al [6] conducted a research concerning the role of discourse signaling cues in L1 listening comprehension. They did find that the presence of signaling cues in the text resulted in a significance increase in the quantity of listeners' notes on both the overall content and major points. The afore-mentioned research [3] that successfully classified discourse signaling cues also draw the conclusion that cues really helped and a more specific finding was that macromarkers proved to be more conductive than micromarkers. A counter research conducted by Flowerdew and Tauroza [7] demonstrated that learners who had listened to a lecture with micromarkers performed significantly better than those who had listened to the lecture without them. Therefore, it remains a considerable space for further researches on the effect of discourse signaling cues in listening comprehension. To date, the most recent study that highlights the important role of discourse signaling cues in L2 listening comprehension is Jung's study [8] which involved 80 Korean learners of English as a Foreign Language. Of the 80 learners, half listened to the lecture with discourse signaling cues, and the other half listened to the lecture without those cues. Half of the learners in each group performed summary tasks; the other half performed recall tasks. The findings showed that discourse signaling cues play an important role in L2 listening comprehension. Compared to the nonsignaled group, the signaled group recalled considerably more accurate high- as well as low-level information from the lecture. Therefore, for non-native speakers, the inability to recognize macrostructure of the academic lecture is thought to be one of the major impediments in understanding lectures.

\section{AUTHENTICITY OF DISCOURSE SIGNALING CUES IN THE TEM 8 LECTURE COMPREHENSION TASKS}

Since discourse signaling cues function as a comprehension facilitator in second language listening, it is important to ensure the authenticity of discourse signaling cues in scripts of academic listening tests. Here, general features of discourse signaling cues of a TEM 8 mini-lecture are compared to those of an authentic academic lecture on a similar topic taken from transcribed academic lectures of Michigan's Academic Spoken Corpus [9] to see if the dimensions of discourse signaling cues match. Basic information of both lectures is presented below:
TABLE I. BASIC INFORMATION OF LECTURES IN THE TESTS

\begin{tabular}{|c|c|c|c|}
\hline & TEM 8 & IELTS & MICASE \\
\hline $\begin{array}{c}\text { Speaker } \\
\text { attributes: }\end{array}$ & native speaker & $\begin{array}{l}\text { native } \\
\text { speaker }\end{array}$ & native speaker \\
\hline $\begin{array}{l}\text { Transcript } \\
\text { attributes: }\end{array}$ & mini-lecture & mini-lecture & $\begin{array}{c}\text { large and long } \\
\text { lecture }\end{array}$ \\
\hline Title: & $\begin{array}{l}\text { What Can We } \\
\text { Learn from Art }\end{array}$ & $\begin{array}{c}\text { Australian } \\
\text { Aboriginal } \\
\text { Rock } \\
\text { Paintings } \\
\end{array}$ & $\begin{array}{l}\text { Renaissance to } \\
\text { Modern Art } \\
\text { History Lecture }\end{array}$ \\
\hline $\begin{array}{l}\text { Academic } \\
\text { division: }\end{array}$ & humanities & humanities & humanities \\
\hline $\begin{array}{l}\text { Interactivity } \\
\text { rating: }\end{array}$ & highly monologic & $\begin{array}{l}\text { highly } \\
\text { monologic }\end{array}$ & $\begin{array}{l}\text { highly } \\
\text { monologic }\end{array}$ \\
\hline Recording date: & 2007 & Before 2011 & $2001-3-21$ \\
\hline $\begin{array}{l}\text { Recording } \\
\text { duration: }\end{array}$ & $\begin{array}{c}6 \text { minutes } 48 \\
\text { seconds }\end{array}$ & $\begin{array}{c}4 \text { minutes } 50 \\
\text { seconds }\end{array}$ & 50 minutes \\
\hline Word count: & 948 words & 668 words & 7951 words \\
\hline
\end{tabular}

In order to classify and quantify discourse signaling cues in the three transcribed texts, an exhaustive and specified category index which is adapted from Jung's study [8] is listed below:

\section{Types of TeXtual Cues}

\section{A. Previews (macro)}

TEM 8 (1): Today's lecture is the very first of a series of lectures on art history. (1)

IELTS (1): I've been invited to talk about my research project into Australian Aboriginal rock paintings. (1)

MICASE (8): we ended the class last time talking about (1) we talked about (2) the real allegory as we discussed (1) today's lecture is about a slightly later period in Paris (1) the artist we'll be focusing on is Edward Mon- Manet (1) we've talked about some of the associations (1) over the course of the period we're looking at today ... (1)

\section{B. Topic markers/shifters (macro)}

TEM 8 (2): I'd like to spend some time discussing with you the following topic. (1) I'd say (1)

IELTS (2): In the Yam period...(1) Size is another characteristic.(1)

MICASE (11): these are more ways he's bringing paradox into this work (1) there's another way that (1) in some ways (1) we begin to see (1) let's move ahead (1) we're getting into me tricky territory (1) let's go back (3) think about the differences (1) another thing is (1)

\section{Summarizers (macro)}

TEM 8 (9): So (2) In short (1) In summary (1) thus (1) therefore (1) In brief (1) To conclude my lecture (1) This brings us to the end of our lecture. (1)

$\operatorname{IELTS}(0)$

MICASE (28): so (25) that's what we've got here (2) that's it for today (1)

\section{Emphasis markers (macro)}

TEM 8 (5): You know (1) The same is true of ...(1) As a matter of fact (1) As we've said (1) what's more important (1) 
IELTS (5): One of the most significant characteristics ...(1) The more recent images...(1)... which is the focus of...(1) It's not surprising then....(1) Even today (1)

MICASE (14): this is certainly something that (1) what it does is to... (1) you know (4) especially (1) it's not (2) in fact (2) for one thing we can notice this (1) that's modernity...bring then here (1) it's not that (1)

\section{E. Exemplifiers (macro)}

TEM 8 (5): like (1) For example (4)

IELTS (1): For example (1)

MICASE (7): like (5) the example of (1) take for example (1)

\section{F. Relators (macro)}

TEM 8 (2): That is (2)

IELTS (0)

MICASE (11): this is supposed to (1) this is (3) that's why (2) that's how (2) that's one way (1) you can see (1) that's not (1)

\section{G. Definition markers (macro)}

TEM 8 (1): we can say

IELTS (0)

MICASE (3): it means (1) this is (1) it's called (1)

\section{H. Rhetorical questions (macro)}

TEM 8 (2): why do we need to study art history? (1) And what can we learn from it? (1)

IELTS (0)

MICASE (4): what does he do? (1) how is this set up? (1) where does that put us as the imaginary viewers? (1) are we missing the slide on the right? (1)

\section{Logical connectives}

a. numerative connectives (macro)

TEM 8 (4): First of all (1) The second point I'd like to make (1) Thirdly (1) This is my fourth point (1)

\section{IELTS (0)}

MICASE (0)

b. intersentential connectives (micro)

TEM 8 (21): But (5) because (1) In addition (1) and (7) also (2) or (1) on the other hand (1) by contrast (1) Similarly (1) Besides (1)

IELTS (8): and (1) But (4) However (1) So (2)

MICASE (225): and (116) but (42) because (15) also (8) again (8) or (19) moreover (3) too (6) yet (6) even (1) furthermore (1) c. temporal connectives (micro)

TEM 8 (2): at the same time (2)

IELTS (0)

MICASE (48): then (9) at the end of that illusion (1) at the same time (3) at the time (2) now (27) at this time (1) today (2) in the meantime (1) finally (2)

d. spatial connectives (micro)

TEM $8(0)$

IELTS $(0)$

MICASE (17): on the left (7) on the right (5) up here (1) here (3) at that same exhibition (1)

\section{J. framing/segmentation markers (micro)}

TEM 8 (2): Ok (1) Oh (1)
IELTS (0)

MICASE (186): um (162) uh (8) oh (3) okay (5) alright (1) i think (3) well (2) yeah (2)

The numbers of categorized discourse signaling cues (based on Jung's study 2003) in the three discourses (TEM 8 test script vs. IELTS test script vs. MICASE script) are contrasted in the following chart:

TABLE II. NUMBERS OF DISCOURSE SIGNALING CUES

\begin{tabular}{|c|c|c|c|}
\hline & $\begin{array}{c}\text { TEM } \\
8\end{array}$ & IELTS & MICASE \\
\hline Previews: & 1 & 1 & 8 \\
\hline Topic Markers: & 2 & 2 & 11 \\
\hline Summarizers: & 9 & 0 & 28 \\
\hline Emphasis Markers: & 5 & 5 & 14 \\
\hline Exemplifiers: & 5 & 1 & 7 \\
\hline Relators: & 2 & 0 & 11 \\
\hline Definition Marker: & 1 & 0 & 3 \\
\hline Rhetorical Questions: & 2 & 0 & 4 \\
\hline Numerative connectives & 4 & 0 & 0 \\
\hline Macromarkers: & 31 & 9 & 86 \\
\hline $\begin{array}{l}\text { Logical Connectives (except numerative } \\
\text { connectives): }\end{array}$ & 23 & 8 & 290 \\
\hline Framing/Segmentation Markers & 2 & 0 & 186 \\
\hline Micromarkers: & 25 & 8 & 476 \\
\hline Total & 56 & 17 & 562 \\
\hline
\end{tabular}

\section{ANALYSIS}

According to the listed numbers, there are altogether 56 discourse signaling cues in the TEM 8 script, 17 discourse signaling cues in the IELTS script, and 562 cues in the MICASE script. The cue/word ratio is $5.9 \%$ in the TEM 8 script, $2.5 \%$ in the IELTS script and 7\% in the MICASE script respectively. The total cue/word ration of the three sample scripts does present some noticeable difference: the IELTS script contains the smallest cue/word ratio. Furthermore, we can also locate some big gaps within a few specific categories. First, in terms of macromarkers, there are 31 macro cues in the TEM8 script, 9 macro cues in the IELTS script, while there are only 86 macromarkers in the MICASE script. The lecture taken from MICASE is a highly monologic lecture which lasts 50 minutes. In order to convey information effectively, presumably, there should be more macromarkers employed to signal the logic and organization of the lecture content, but quite out of expectation, there are not many macromarkers in the lecture under discussion and there's no numerative connective in it. The MICASE script has been closely read through in order to probe into the reason for limited use of macromarkers. One explanation could be that the authentic lectures now are usually equipped with slides which help arrange the whole lecture in a cohesive manner and therefore the numerative connectives can be omitted. Nevertheless, when testers write listening test materials, they must make sure that test-takers can follow the audio lecture which is considered academic and abstract, so due macromarkers are indispensable for the test-takers without any visual aid. Another explanation is that the three scripts deal with the same topic "art" from different perspectives - the mini-lecture in TEM 8 talks about the types and functions of art, and the one in IELTS concerns categories of Australian aboriginal rock paintings which are 
supposed to be numerated while the other (MICASE) talks about the history of oil painting, more specifically, some representative art works in different periods of history in a chronological order. With the help of slides, the lecturer can focus on elaboration of paintings instead of presenting an overview of the art history.

As regards micromarkers, there are only 25 micro cues in the TEM 8 script, 8 micro cues in the IELTS script, while there are 476 cues in the MICASE script, particularly within the category of framing/segmentation markers. Note here, there is no framing mark in the IELTS script and only 2 framing marks in the TEM 8 script. And on the whole, the IELTS script witnesses the smallest category of discourse signaling cues, only covering 5 types, namely, preview, topic marker, emphasis marker, exemplifier and intersentential connectives. Therefore, here poses a question worth further investigationare there insufficient discourse signaling cues, especially micro discourse signaling cues in the listening tests of TEM 8 and IELTS?

For high-stake tests such as TEM 8 and IELTS, authenticity is a crucial factor to be considered. A conspicuous feature of an oral speech distinct from a written one is the rich use of framing or segmentation markers such as "um, uh, ok, etc." Therefore, ensuring authenticity of listening materials is quite a challenge if the related test item writer attempts to mode written materials into listening materials. Directly transcribing an authentic academic lecture might be a safer way, but it is not easy to locate an authentic lecture of the proper difficulty level and of a suitable topic; hence rewriting written materials is still the most practical and economical way for listening test writers. In order to render the audio lecture more authentic, it is suggested that the speaker assigned the task to read the lecture material needs to add proper discourse signaling cues when necessary instead of mechanically reading through the written script.

\section{CONCLUSION}

Discourse signaling cues play an essential role in lecture comprehension. Through contrasting the discourse signaling cues of an authentic lecture transcription taken from MICASE, a mini-lecture transcription taken from a TEM 8 listening subtest, and a mini-lecture transcription taken from an IELTS listening subtest, we have found some noticeable differences between them in terms of the quantity as well as the pattern of discourse signaling cues. The findings show that there is a higher frequency of macromarkers and a lower frequency of micromarkers in the test scripts. In order to improve authenticity of academic listening tests, it is important to refer to transcriptions of authentic academic lectures and add authentic discourse signaling cues to the test scripts; otherwise, the test-takers' listening comprehension might be hindered.

\section{REFERENCES}

[1] A. Tyler, "The role of syntactic structure in discourse structure: Signaling logical and prominence relations," Applied Linguistics, Vol. 15, pp 243-262, 1994.

[2] T. A. van Dijk, Strategies of Discourse Comprehension. New York, Academic Press Inc., 1983.

[3] C. Chaudron and J.C. Richards, "The effect of discourse markers on the comprehension of lectures," Applied Linguistics, Vol. 7, pp.113-127, 1986.

[4] S. Thompson, "Text-structuring metadiscourse, intonation and the signaling of organization in academic lectures," Journal of English for Academic Purposes, Vol. 2, pp 5-20, 2003.

[5] L. Pickering, "The structure and function of intonational paragraphs in native and nonnative speaker instructional discourse," English for Specific Purposes, Vol. 23, pp 19-43, 2004.

[6] J. P. Rickards, B. R. Fajen, J. F. Sullivan and G. Gillespie, G., "Signaling, note-taking, and field independence-dependence in text comprehension and recall," Journal of Educational Psychology, Vol. 89, pp 508-517, 1997.

[7] J. Flowerdew and S. Tauroza, "The effect of discourse markers on second language lecture comprehension," Studies in Second Language Acquisition, Vol. 17, pp 435-458, 1995.

[8] E. H. Jung, "The role of discourse signaling cues in second language listening comprehension," Modern Language Journal, Vol. 87, pp 562577, 2003.

[9] Michigan Corpus of Academic Spoken English, English Language Institute, University of Michigan.

http://quod.lib.umich.edu/cgi/c/corpus/corpus?c=micase;page=mbrowse . 